\title{
Error Analysis in Solving the Rational and Irrational Inequalities
}

\author{
Yunia Bani Pratiwi ${ }^{1}$, Rizky Rosjanuardi ${ }^{2}$ \\ \{yuniabanipratiwi@upi.edu ${ }^{1}$, rizky@upi.edu ${ }^{2}$ \} \\ Program Studi Pendidikan Matematika, Sekolah Pascasarjana Universitas Pendidikan Indonesia, \\ Jl. Dr. Setiabudi No. 229, Bandung 40154, Indonesia ${ }^{1}$, Departemen Pendidikan Matematika, \\ Universitas Pendidikan Indonesia, Jl. Dr. Setiabudi No. 229, Bandung 40154, Indonesia ${ }^{2}$
}

\begin{abstract}
This research aims to analyze students ' answers in rational and irrational inequalities. A qualitative method was used in this research. Data were collected from 42 students of $10^{\text {th }}$ grade through the test consisted of 10 problems. The result showed two groups of students' solutions. The first is students who used a number line and the second is students who solve directly without the number line. There are six categories of student errors i.e. solving rational inequality, looking for zero makers in numerators and denominators of rational inequality, errors arose from problems with factorization, wrong in applying the property of distribution, ignoring irrational inequality rules, and misinterpreting the sign of inequality. We conclude the use of number lines is enough to help students in solving rational and irrational inequality if students understand the rules of rational and irrational inequalities and able to interpret the sign of inequalities on the number line.
\end{abstract}

Keywords: Student's answers, Errors, Number Line, High School Students, Rational and irrational inequalities

\section{Introduction}

Inequality is part of algebra. Algebra is one of the most essential topics in mathematics because its application is very fundamental and integrated into other conceptual concepts in mathematics [1]. The success of studying inequality will facilitate the learning of the next mathematics concept. Algebra is the way we express generalizations about numbers, quantities, relations and functions [2]. A good understanding to connect numbers, quantities, relations and functions is related to success in using algebra. The basics of calculating operations are needed in inequalities where are the backbones of many concepts and mathematical areas [3].

Recent research on school algebra has included a focus on students' understanding of and approaches to inequalities [4]. One example of this research on the topic of inequalities includes research conducted by Botty et al. [5] on year 9 in the secondary schools in Brunei Darussalam. The primary focus of this study is to investigate which area or items that the students find easy or difficult. The results of his research showed that students are confused with the value of negative integers. Most students answered -12 is less than -21 . There are also, students who made mistakes because they were careless. For example, students are asked to draw $x<-1$. Students knew that the value decreases but students drew the number line to the right. These mistakes can be considered as carelessness. Students had poor basics in solving algebraic 
equations. Those who made mistakes were mostly because of the change of sign when dividing the other side with a negative integer and careless mistakes when dividing positive integer with a negative integer to form a positive value [5].

Another research was conducted by Taqiyuddin et al. [6] which unveils how junior high school students answer $9 x+1>9 x-2$. The result shows that the majority approached the question by doing algebraic operations. For example, one of the students subtracted both sides of the equation by $9 x$ and 1 by writing down $9 x-9 x$ into $x$ instead of 0 . In the next step, $-2-$ 1 is simplified into -3 . Interestingly, he simplified $9 x-9 x$ becomes $x$ instead of 0 . Most of the students incorrectly answer the question in conducting the algebraic operation. In addition, there are also those who only rewrite questions, interpret inequalities into words, or blank answers [6]. Errors in students' answers were similar to the research conducted by Botty et al. [5] and Taqiyudin et al [6] also unveiled in research conducted by Saputro et al. [7 ] in one junior high schools, Indonesia. A problem in the study, students were asked to find the value of $y$ if $y=100-\frac{100}{1-t}$ when $t=9$. A student simplifies the terms of algebraic expressions that only contain variables because the student answered $y=10$ when he substitutes $t=9$. There are also, a student does not use fractional reduction rules with integers correctly. Student who respondent $\frac{0}{10}$, have a misunderstanding of integer execution operations by fractional numbers [7]. This study showed that students had poor basics in solving algebraic equations.

Based on the research conducted above, this research will analyze the students' answers in solving rational and irrational inequalities. Most of the books used by students refer to rational inequalities as inequality of fraction forms. Understanding the concept of rational numbers or fractions greatly affect student performance because rational numbers are one of the most important types of knowledge needed in learning [8]. This rational inequality has the general form $\frac{f(x)}{g(x)}<0, \frac{f(x)}{g(x)}>0, \frac{f(x)}{g(x)} \leq 0$, or $\frac{f(x)}{g(x)} \geq 0$ where $f(x)$ and $g(x)$ are functions in $x, g(x) \neq$ $0, \forall x \in R$. Some students solve inequalities such as solving equality and students have big problems in solving inequality [9]. Another study in early mathematics university students in Italy [10] which showed some students fail to describe inequalities such as $\frac{x^{2}-1}{x}>0$ There are also irrational inequalities which are more commonly referred to as form inequalities the root or inequality of variables that are included in the root sign. In a variety of mathematics textbooks, high schools found a collection of kinds of irrational inequality i.e $\sqrt{u(x)}<a$, $\sqrt{u(x)} \leq a, \sqrt{u(x)}>a, \sqrt{u(x)} \geq a, \sqrt{u(x)}<\sqrt{v(x)}, \sqrt{u(x)} \leq \sqrt{v(x)}, \sqrt{u(x)}>\sqrt{v(x)}$, or $\sqrt{u(x)} \geq \sqrt{v(x)}$ where $a \geq 0$ and $u(x)$ and $v(x)$ are functions in $x$ provided that $u(x) \geq 0$, and $v(x) \geq 0$. In solving this rational and irrational inequality, students were asked to use a number line to find the inequality solution because the teacher always gives them to make a number line set to solving inequality. But there are some students who do not understand how to interpret the number line. This is quite relevant to the statement of Woods et al. [11] which describes some students may need guidance in interpreting number lines or maybe to work using number lines. Systematically, modeling mathematical concepts in a number line and teaching students how to represent the lines above might encourage students to understand the initial concepts of mathematics.

Bagni [12] conducted research on students 16-17 years old (the II class or in the III class of the Italian Liceo Scientifico). The results showed that many students are conditioned to apply always the "standard" rules given by the teacher. This also reinforces the reason that students tend to do what their teacher does including using number lines in solving inequalities. 
From the above explanation, it can be concluded that the topic of rational and irrational inequalities is important to investigate because of several factors, i.e. the topic of rational and irrational inequalities is one part of algebra that is important to study. In addition, based on the results of previous studies found errors of students in solving solutions to rational and irrational inequalities where the topic of rational and irrational inequality is also a supporting concept to other topics on mathematics. Errors will always be there since errors are part of learning and learners are learning all the time. This means that teachers must always research on learner errors [13]. Research on errors in this rational and irrational inequalities needs to be analyzed so that it can be corrected through subsequent learning.

\section{Methods}

This research aims to analyze students" answers to solving rational and irrational inequalities. A qualitative method was used in this research. Data were collected from 42 students of $10^{\text {th }}$ grade through the test consisted of 10 problems. First, students were asked to solve a set of rational and irrational inequalities problems. Students had a break after the written test. Next, the interviewer selected students for additional individual interviews to gather more detailed data to analyze the reasons for students' ${ }^{6}$ answers. The interviews were conducted on the same day as the written test. The interviewer did not intervene to get correct or incorrect solutions. As a guideline for carrying out the interviews, general starting questions and followup questions had been prepared to both focus on investigating students ' error and to allow flexibility during the interviews. The general interview questions included:

a. Do you understand this problem?

b. Could you explain your solution?

c. Why did you take this step?

d. What did you mean by this step?

e. What is the next step?

f. How do you check whether your solution is correct or not?

The former type of questions was used at the beginning of an interview, and the latter was used while the interview was taking place and depended on students' responses. If a student did not solve one of the tasks, the interviewer asked whether he or she understood the task and then asked further questions depending on his or her reactions.

\section{Result and discussion}

It was found that many students experienced errors in solving rational and irrational inequalities problems. This can be seen in the results of tests that have been done, there are students who answered correctly under $50 \%$ of the total respondents. In explaining the types of students' answers, the researcher uses simple problems that students should have mastered to make it easier to answer other more complex problems.

Figure 1 is a graphic of the percentage correct answers from students who use the number line in solving inequality and without do not use the number line. From the graphic above, we get that 8 out of 10 problems, students who answer correctly use more numbers to solving inequalities problems. 


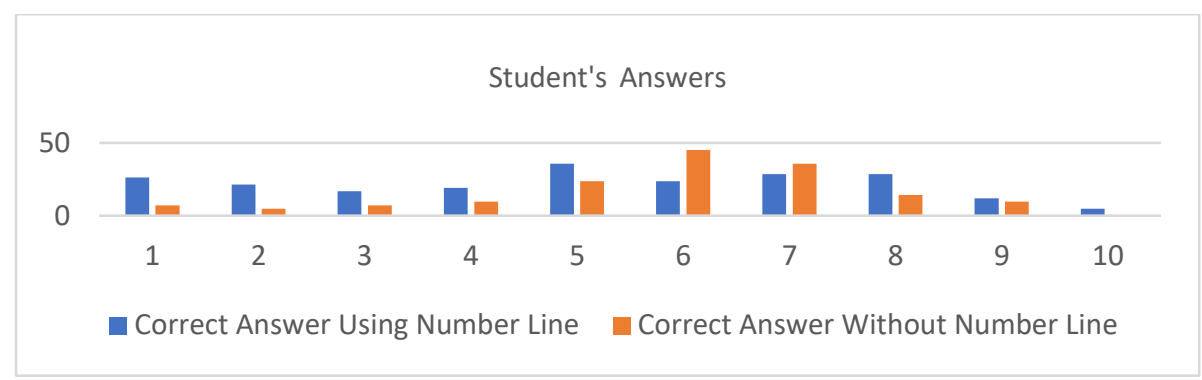

Fig. 1. Graphic of student's answers

\subsection{Student's answer using a number line}

There are some errors seen in students who use number lines in solving inequality. However, it turns out that the error that occurred was not in interpreting the number lines but since the students did the arithmetic operations. For example, in problem number 5 as shown on Figure 2, which is to solve $\frac{3 x-2}{x}<x$, students first subtract the two sides with $x$ then separate the numerator and denominator into $-x^{2}+3 x-2<0$ and $x<0$. Then students count them one by one. The sign of inequality follows the problem. In completing the quadratic form, students multiply the inequality $-x^{2}+3 x-2<0$ with -1 . Based on the results of the interview, students explained this was done in order to make it easier in factoring when the variable of $x^{2}$ is positive. However, students are still wrong in factoring. These $11^{\text {th }}$-grade students still cannot make the quadratic factor even though the factoring skills were taught earlier in grades 9 and 10. This is a problem because factorization is the basic skill that a person needs to be able to overcome problems related to mathematics later in further education [13].

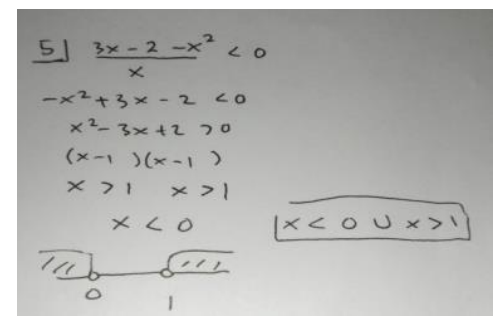

Fig. 2. Student A's answer

The way that these students do is similar to the answers of students in research conducted by Anggoro \& Prabawanto [14]. Students are wrong in solving inequality $(x-1)(x+1)>0$ as shown in Figure 3. The student writes $(x-1)>0,(x+1)>0$. The student does not find an inequality solution because it tends to take steps to solve it like in the equation problem.

Other students' answer, they multiply both sides by $x$. Then write it in the form of quadratic inequality and $x \neq 0$. At the end of the answer, students draw two number lines. When researchers ask why he solved it like that. Students answer that for inequality to be positive, both values must be positive or both are negative. Students also understand that in problem number 5 there is a condition $x \neq 0$. However, the student did not check whether $x<0$ is the solution to inequality. 


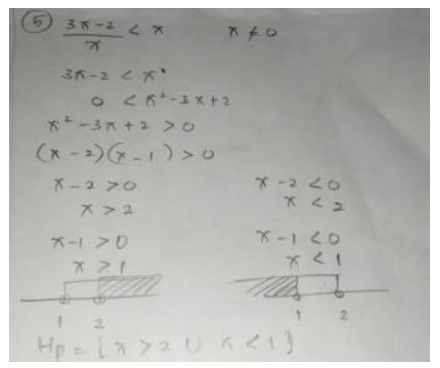

Fig. 3. Student B's answer.

There are also students who did algebraic operations correctly but they incorrectly drew a number line like problem number 10 as shown on Figure 4. Students solve the inequality $\sqrt{x}+$ $\sqrt{x+1}<3$. The student is able to calculate correctly, and use the rules rational inequality correctly but incorrectly in drawing a line number $x<\frac{16}{9}$, so that the inequality solution obtained is wrong.

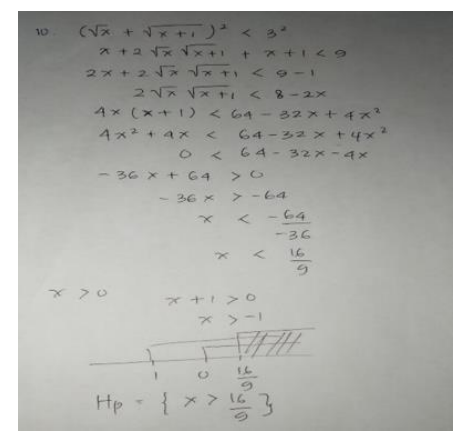

Fig. 4. Student C's answer.

The same thing happened to the inequality problem $\sqrt{x+3} \leq 3$ as can be seen on Figure 5. Students are correct in performing algebraic calculation operations, but at the end of the answer, students are wrong in describing the solution in a number line. The student has done algebraic operations correctly but they misinterpreted the sign of inequality in the number line. Inequality $x \leq 6$, students interpret by drawing a number line whose direction is to the correct.

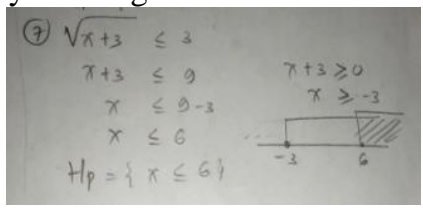

Fig. 5. Student D's answer.

\subsection{Student's answer without number line}

In the rational inequalities problem $\frac{2}{x-3}>\frac{3}{x+2}$ as can be seen on Figure 6, students do similar manipulation as if it was an equation problem. Students ignore zero makers on the 
denominator. Students also do not make a number line in solving inequality because students think that there is only one value that makes true.

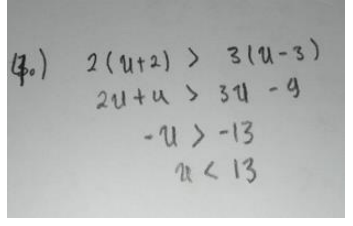

Fig. 6. Student E's answer.

The way to answer the inequality problem is almost similar to the way to answer the Preparatory year students at King Saud University. Based on the literature, this error is called errors due to finding and writing the solution set [15]. In the study, students were given problems $\frac{x-1}{x}>2$. Then students write $\frac{x-1}{x}>2 \Rightarrow \frac{x-1}{2}=2 \Rightarrow x-1=2 x \Rightarrow x>1$

Furthermore, for problem number 10 (Figure 7) more than $50 \%$ of students answer without using a number line and the mistakes made are almost the same. Based on the results of the researchers' analysis, students make mistakes in applying the properties of the multiplication distribution between two forms of algebra.

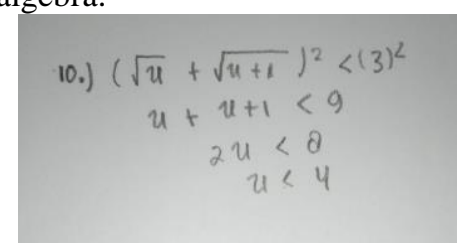

Fig. 7. Student F's answer.

There are also other students' answers that are correct in applying the distributive properties of multiplication but when the final stage of completion students ignore the rules that the numbers in the roots must be positive. Here is one example of students ' answers to problem number 10 as can be seen on Figure 8.

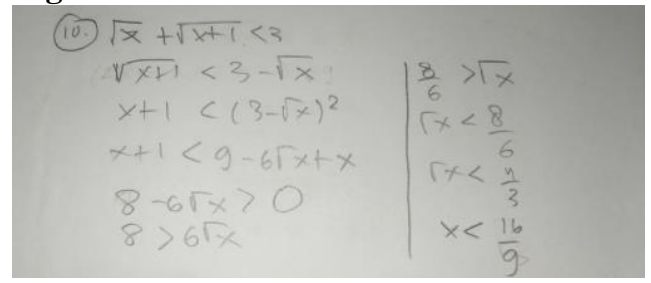

Fig. 8. Student G’s answer.

When it is to answers $x<\frac{16}{9}$, students do not write rules irrational inequalities. The student justifies the answer given by saying, " I forgot the condition for the root ". Researchers suspect students forgot it because this research was conducted while learning in class is focusing on other material that is rarely related to rational and irrational inequalities so students become forgotten. This shows that the students' learning processes may lack the conceptual understanding that might have prevented them from forgetting [16].

It is not only in problem number 10, but most students also ignore the rules of the numbers in the root. As seen in problem number 7 (Figure 9), in answering the inequality solution 
$\sqrt{x+3} \leq 3$ most students make the errors of ignoring the condition that the function in the form of roots must be greater than zero.

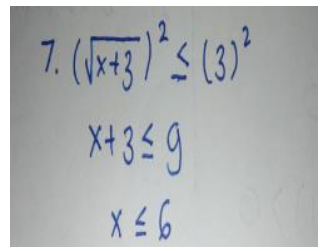

Fig 9. Student H's answer.

The same thing was done also on problem number 8 (Figure 10). More than $50 \%$ of students did not write the terms of irrational numbers i.e. $x-3>0$ and $7-x>0$.

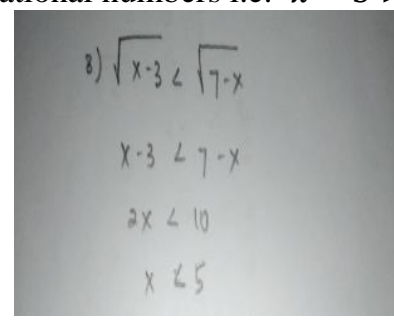

Fig 10. Student I's answer.

For problem number 8 (Figure 11), most students do not use the number line because based on the results of the interview, students think there is only one value to solving rational inequality. Students ignore the conditions of the root numbers. However, the student answers incorrectly when working on problem number 8 without using a number line. Students calculate correctly, but at the end of the students answer incorrectly inferring the inequality solution.

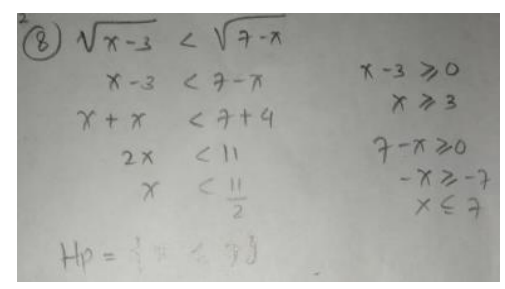

Fig. 11. Student J's answer.

\section{Conclusions}

There are two types of students' answers to solving rational and irrational inequality. That is students who use the number line and without number line. There are six categories of student errors when looking for rational and irrational inequalities' solutions i.e. students solve rational inequality problems like an equation problems, students look for zero makers in numerators and denominators of rational inequality with the inequalities following the problem, students make errors arose from problems with factorization, students make errors in applying the property of distribution, ignoring irrational inequality rules. students ignore irrational inequality rules and 
students misinterpret the signs of inequality into the number line From the students' answers above, we concludes that the use of number lines is enough to help students in solving rational and irrational inequality if students understand the rules of rational and irrational inequalities and able to interpret the sign of inequalities on the number line.

Acknowledgment. We would like to thank students and teachers of Alfa Centauri High School in Bandung, Indonesia for their contribution to this study. Hopefully, this research can be useful for national education.

\section{References}

[1] Usiskin, Z.:Why is Algebra Important to Learn? American Educator, Spring, pp.30-37. (1995)

[2] Watson, A.: Key Understanding in Mathematics Learning. University of Oxford: Nuffield Foundation. (2007)

[3] Halmaghi, E. \& Liljedahl, P.: Inequalities in the History of Mathematics: From Peculiarities to a Hard Discipline. GeoGebra International Journal of Romania, 4(2), 43-56. (2015).

[4] Kieran, C.: The Equation / Inequality Connection In Constructing Meaning For Inequality Situations. In Proceedings of the 28th Conference of the International Group for the Psychology of Mathematics Education, Vol I pp 137-166. (2004)

[5] Botty, M.R.H., Yusuf J., Shahrill M., \& Mahadi, M.A.: Exploring Students' Understanding on 'Inequalities'. Mediterranean Journal of Social. (2015)

[6] Taqiyuddin M., Sumiaty E, \& Jupri A. : Analysis of junior high school students' attempt to solve a linear inequality problem. The 4th International Conference on Research, Implementation, and Education of Mathematics and Science. (2017)

[7] Saputro, B.A., Suryadi, D., Rosjanuardi, R. \& Kartasasmita, B.G.: Analysis of Students' Errors in Responding to TIMSS Domain Algebra Problem. IOP Conf. Series: Journal of Physics: Conf. Series 1088. (2018)

[8] National Mathematics Advisory Panel.: Final Report: Foundations for Success. Western initiative for strengthening education in math. (2008)

[9] Tsamir, P., \& Bazzini, L.: Consistencies and inconsistencies in students' solution to algebraic 'single-value' inequalities. International Journal of Mathematical Education in Science and Technology, 55, 793-812. (2004).

[10] Boero, P., \& Bazzini, L.: Inequalities In Mathematics Education: The Need For Complementary Perspectives. Proceedings of the 28th Conference of the International Group for the Psychology of Mathematics Education, Vol I pp 137-166. (2004)

[11] Woods, D. M., Geller, L.K. \& Basaraba, D.: Number Sense on the Number Line, Intervention in School and Clinic, 53(4), pp. 229-236. doi: 10.1177/1053451217712971. (2018)

[12] Bagni, G.T.: Irrational Inequalitions: Learning and Didactical Contract. In Gagatsis,A. \& Rogers, L. (Eds). Didactics and History of Mathematics (pp.133-140). Erasmus ICP-95-G-2011/11, Thessaloniki. (1996)

[13] Makonye, J.P., \& Nhlanhla, S. Exploring 'Non-Science' Grade 11 Learners' Errors in Solving Quadratic Equations. Mediterranean Journal of Social Sciences Vol.7 No.12. (2016)

[14] Anggoro, A. \& Prabawanto, S.: Undergraduate Students' Conceptual Understanding On Rational Inequalities. IOP Conf. Series: Journal of Physics. (2019)

[15] El-Khateeb, M.M.A.: Errors Analysis of Solving Linear Inequalities among the Preparatory Year Students at King Saud University. Journal of Education and Practice. (2016)

[16] Jupri, A., Drijvers, P. \& Panhuizen, H.: Mathematics Education Research Group of Australia, 26, 683710, (2014) 